\title{
Participatory Innovation and Prototyping in the Cultural Sector: A case study
}

\author{
Stefania Boiano \\ InvisibleStudio LTD \\ London \\ UK \\ stefania@invisiblestudio.net
}

\author{
Ann Borda \\ Health and Biomedical Informatics Centre \\ The University of Melbourne \\ Melbourne, Australia \\ aborda@unimelb.edu.au
}

\author{
Guiliano Gaia \\ InvisibleStudio LTD \\ London \\ UK \\ giuliano@invisiblestudio.it
}

\begin{abstract}
This paper explores the growing pervasiveness of forms of participatory innovation in the cultural sector, with a particular focus on the integration of prototyping approaches. Participatory uses of prototyping are underpinning new developments and opportunities for museums and galleries in transforming both internal and public involvement in the co-design of services and engagement. This transformation is illustrated through landscape perspectives and real-world learnings.
\end{abstract}

Participatory innovation. Prototyping. Museums. Design thinking.

\section{INTRODUCTION}

The concept of participatory innovation generally takes on the form of an integrated approach that cuts across different approaches about how organizations can meaningfully involve their audiences and other stakeholders in innovation (Dawson 2017).

Participatory innovation is aligned to a suite of methods and contextual processes, which can be applied across different sectors. Specifically, the concept of participatory design arose in Scandinavia in the 1980s as a form of cooperative design or collective resource approach in which strategies and techniques were developed for workers to influence the design and use of information and communication technologies (ICT) in the workplace (Bodker et al. 2004, Buur \& Matthews 2008, Cross 1992). This approach has evolved into design and development processes in which stakeholders are invited to participate and contribute on an equal footing, not simply as critics and evaluators of product and system concepts, but as co-designers (Buur \& Matthews 2008, Anttiroiko 2016). So-called co-design (as the now commonly applied term) is closely associated with human-centred design processes (Szebeko \& Tan 2010). According to Buur and Matthews (2008), a participatory Innovation project is characterised by five types of activities organised in a cross disciplinary innovation team that involves key stakeholders in an organization or group in which the team is embedded; Such activities can include Field study; Sense-making: Co-Ideation; Business modelling; and Co-design. Rather than data-driven and analytical processes that decision-makers often use, these activities take on a humanoriented, situational perspective to explore daily living, relationships, behaviours, actions and context. Typically, the co-design stage allows for evaluating and communicating the potential of these ideas and strategies, which arise in previous stages, and the use of tools such as concept sketches, scenarios, and prototypes, for example (Bodker et al. 2004, Buur \& Matthews 2008). These guide stakeholders and users in taking abstract ideas, concepts, and suggestions and making them into tangible outcomes.

The seminal publication, Participatory Museum by Nina Simon (2010) outlines approaches for museums to become more open to participation, involving users to inform, co-design, and innovate projects and programs, as well as providing platforms for users to construct their own meanings with the institution. Closely related to these concepts is the notion of open innovation, a recent concept coined by American organizational theorist, Henry Chesbrough, which focuses on organisational engagement with a wide range of stakeholders and their perspectives to develop better products or services (Chesbrough 2003). Haitham Eid (2016) discusses a theoretical framework for an innovation model specific to museums based on three interconnected concepts 
of (1) open innovation, (2) social enterprise, and (3) social innovation, each of which are growing trends in the museum sector. Together they represent a formula for innovation in museums; namely those museum institutions, which adopt a social enterprise business model and utilise open innovation strategies, are better adept at achieving social innovation.

Globally, the GLAM (Galleries, Libraries, Archives and Museums) sector has been embracing 'open' movements - open access, open data, open source, and open science, among others (Dawson 2017). OpenGLAM, for example, is a global network of people and organisations who are working to open up content and data held by GLAM institutions to create a cultural commons.

Such trends have elicited new forms of participation, innovation, and engagement, as well as methods of involving not only traditional visitors or users, but also multiple stakeholders, such as academia, industry, government, and other cultural organizations.

\section{PROTOTYPING}

If we truly want to understand and influence how corporate cultures create valuable new products, we need to understand more fully the role that culture plays in creating new prototypes (Schrage 1996).

Prototyping is a particular activity that has been increasingly applied over the last decade through visualization and design thinking methods, and provides a means of rapidly innovating cultural services with low resource, such as digital exhibitions and visitor engagement (Turnbull 2011). Mitroff-Silvers (2014) defines 'prototyping' as the practice of building low-fidelity representations of products, services, or experiences in order to learn and test before proceeding. In the museum sector, it has been regularly applied to the context of exhibition interactives, websites and signage, but can also relate to other digital products, interactions, and internal processes. The Minneapolis Institute of Art, for instance, has been rethinking its organizational innovation approach by creating an agile work environment to support a culture of rapid iteration and experimentation (Hegley et al. 2016), and the British Museum has adopted a process of running sprints (Mitroff Silvers 2016).

\subsection{Design thinking}

Prototyping is most often an integral part of a human-centred design method called design thinking. Design thinking refers to structured processes that encourage creativity in problem- solving. Research in design thinking can be traced over several decades (Cross 1992), leading to its validation in organisational processes, for example, as part of the 'Unified Innovation Process Model for Engineering Designers and Managers' developed by the product consultancy IDEO, and in the establishment of the Hasso-Plattner-Institute of Design (d.school, https://dschool.stanford.edu/) at Stanford University in California in 2005 (Plattner 2011). The Stanford-based d.school initially trained engineers and scientists to become innovators, and its approach has since become a pervasive method that brings together a set of principles that include empathy with end-users, rapid prototyping, and a tolerance for failure (Plattner 2011, Merritt 2017).

In recent years it has been successfully adapted as a tool for fostering creativity and solving complex problems by a generation of cultural organisations. For example, Design Thinking for Museums is a web portal (Mitroff Silvers 2013, Mitroff Silvers et al. 2014), which shares relevant case studies in the sector, blog posts and resources. It grew out of a 2012 partnership between the San Francisco Museum of Modern Art and Stanford University's d.school.

\subsection{Prototypes at scale}

Prototyping also appears at different scales with the rise of makerspaces and Fab Labs becoming an international phenomenon, and the global presence of Living Labs that are bringing "together interdisciplinary experts to develop, deploy, and test - in actual living environments - new technologies and strategies for design that respond to this changing world" (Lepik, Krigul \& Terk 2010).

\subsubsection{Maker spaces and Fab Labs}

The rise of open fabrication and prototyping spaces is an international phenomenon that is advancing invention among different stakeholders and are becoming recognised as sites of civic and social innovation. In the U.S., The Institute of Museum and Library Services has invested in a national makerspace programme in libraries and museums, partnering with the Children's Museum of Pittsburgh and San Francisco's Exploratorium to support hands-on, mentor-led learning and STEM skills (https://www.imls.gov/issues/nationalissues/making).

The Maker Lab in Chicago (https://www.chipublib.org/maker-lab/) is one of the first free and publicly accessible maker spaces in the U.S. situated in the Harold Washington Library Center. The Maker Lab features introductory workshops and an open shop for personal projects and collaboration. 


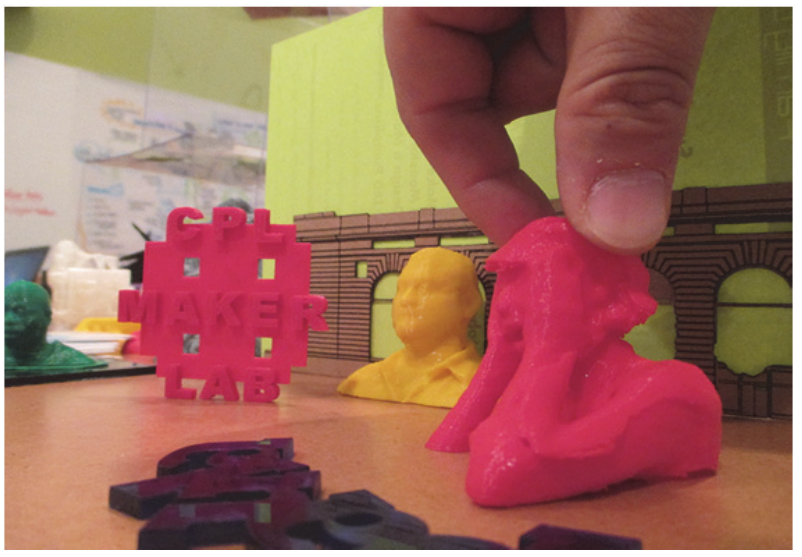

Figure 1: Makerspace, Harold Washington Library Center, Chicago. Source: Flickr, ChiPubLib, Makerspace, October 18, 2013.

In some museum organisations, maker spaces host hackathon events, such as the Museum VX Hackathon collaborative of The Canadian Museum of History and the Canadian War Museum (http://museumvx.ca/). Hackathons are examples of a participative event, often involving a mix of public and museum staff, based on the maker movement and rapid prototyping, resulting in digital products or prototypes (Rey 2017).

Fab Labs are a scaled type of maker space that enables the development of intellectual and fabricated materials using advanced digital tools, e.g. computers and circuit boards, design software, 3D and additive printers, laser cutters, and other resources, such as milling and soldering tools. The Fab Lab movement has been principally led by Massachusetts Institute of Technology (MIT) Center for Bits and Atoms. The Fab Foundation (http://fabfoundation.org/) is the worldwide network that facilitates and supports Fab Lab members in an open, creative community approach to education and enterprise.

An early learning Fab Lab (https://bayareadiscoverymuseum.org/exhibits/fab$(\mathrm{lab})$ is part of the Bay Area Discovery Museum. The lab focuses on learning and enabling children to intentionally build science, technology, engineering, and math (STEM) skills through hands-on learning. Exhibit entry is free for members and included in the price of museum admission.

There are Fab Lab members on every continent that are innovating at local and wider contexts. The Wanger Family Fab-Lab at Madatech Israel (https://www.madatech.org.il/en/fab-lab) National Museum of Science, Technology and Space in Haifa, Israel, features 350 square meters of fab space, and is one of the largest 3D printing fab-labs in the world. Fab Lab Barcelona, based at the Institute for Advanced Architecture of Catalonia, is the headquarters of the global coordination of the Fab Academy program and its own programming supports different educational and research programs related to the multiple scales of the human habitat.

Fab Labs in Sub-Saharan African offer educational objectives that compensate for the lack of equipment in universities, or for women, to facilitate their social and professional integration (Leyronas 2018). For example, the Blolab in Bénin (http://www.blolab.org/) has the objective of promoting digital literacy among young people and local professionals (e.g. artisans, farmers), as well as helping them build inexpensive, accessible and rapidly developed solutions (Leyronas 2018).

\subsubsection{Living Labs}

Living Labs were developed as a concept around the 1990s and pioneered by the Massachusetts Institute of Technology (MIT) and Georgia Tech in the U.S. to bring "together interdisciplinary experts to develop, deploy, and test - in actual living environments - new technologies and strategies for design that respond to this changing world" (Lepik, Krigul \& Terk 2010; Eskilinen et al. 2015).

An example of an early cultural-led living lab was the Creativity and Cognition Studios (CCS) at the Powerhouse Museum in Sydney, which launched an initiative in 2004 called Beta_space. Beta_space was an experimental exhibition area within the Powerhouse, which extended the interactive art research studios of CCS into the public context showing interactive artworks at different stages, from early prototype to end product (Muller 2006).

The development of Living Labs in Europe accelerated over the past decade, largely due to targeted national and European Policy and Innovation initiatives, e.g. the 2020 Policy Frameworks and Digital Agenda that prioritised placing the user at the centre of the innovation lifecycle within real-life settings. The European Network of Living Labs (ENoLL) is the largest formalised entity of Living Labs worldwide. Among relevant areas of thematic work of ENoLL is "Culture \& creativity" providing an arena of experimentation and prototyping in which citizens partnering with industry and public sectors are tasked with overcoming societal challenges using design driven co-creation processes to develop products and services. Examples of cultural partnerships that are part of the ENoLL network include: Barcelona City's Barcelona Laboratori (http://www.openlivinglabs.eu/livinglab/barcelonalaboratori) which is working within the wider context of culture, including science, technology and arts, in promoting and activating "Creativity and Innovation" in the city. SAT Montreal in Canada was founded in 1996 as the Society for 
Arts and Technology (SAT). SAT is a hybrid cultural institution, combining venue, artist residencies, research laboratories and a training centre.

Outside of ENOLL, the Living Laboratory (http://www.livinglab.org) at the Museum of Science in Boston, U.S. has been operational since 2005 and has connected the public with child development research by collaborating with local research institutions, including Harvard University, Boston College, Tufts University, Northeastern University, Boston University, Children's Hospital and others. Deliverables include hands-on child development activities for museums to use with caregivers, a program implementation toolkit, and professional development events for museum and research professionals. Similarly, the Living Lab at the Canada Science and Technology Museum in Ottawa is collaborating with the University of Ottawa on language and cognitive child development studies.

Vilariño and Karatzas (2018) describe a Library Living Lab initiative at the Public Library of Miquel Batllori Volpelleres in Sant Cugat del Valles Barcelona. The Library Living Lab brings together various stakeholders around the public library with the aim of exploring new methods and tools that allow users to better enjoy culture both individually and collectively. The Library Living Lab has implemented a diverse set of activities; such as The Library Visits the Museum, which seeks to break down the walls that separate museums and libraries; and the Interest Group on Educational Apps that investigates learning methods and tools using mobile apps in schools (Vilariño \& Karatzas 2018).

\subsubsection{Startups and incubators}

Startups and accelerators have become an integral part of regional and district innovation economies. They also have enormous potential for cultural institutions to move into the centre of participatory innovation (Ciecko \& Turoczy 2017, Murphy 2018). An early prototype is the EMC Arts Innovation Labs in the U.S. (http://emcarts.org/programs/innovationlabs), which has been described as "a deep dive program for museums, performing arts organizations, and arts development agencies experimenting with new practices."

Beyond the co-working model, museums investing in startups is currently a paradigm shift that is slowly gaining growth (Ciecko \& Turoczy 2017, Murphy 2018). Of the museums that are developing a presence, The New Museums' NEW INC incubator in New York (http://www.newinc.org/) is an experimental initiative of the New Museum launched in 2014. NEW INC is a shared workspace and professional development program that has brought together over 100 cultural practitioners and creative entrepreneurs, including tenants Rhizome and Columbia University's GSAPP Incubator.

In 2016, the Australian Centre for the Moving Image (ACMI) in Melbourne, Australia, launched ACMI X (https://www.acmi.net.au/acmi-X/) as a new co-working space that assembles a mix of filmmakers, digital and visual artists, digital producers, web developers, screenwriters and designers to foster experiments in media, technology \& user experience. Te Papa, the national museum of New Zealand, launched Mahuki (http://www.mahuki.org/) in 2016 to accelerate local startups focused on developing world-leading digital businesses for the GLAM sector.

Most recently The Museum of the Future in Dubai has announced a new accelerator programme to create visitor experiences. The museum, currently under construction, sees itself as a "unique incubator" for futuristic design and innovation, and as a platform to demonstrate and test upcoming inventions and prototypes (Bridge 2018).

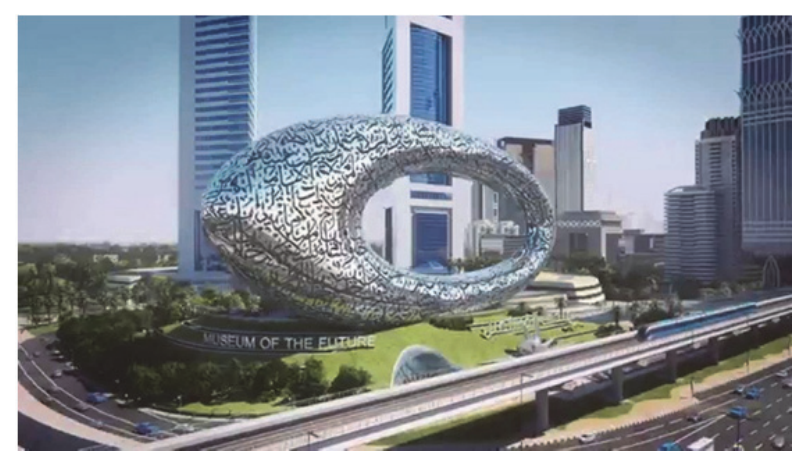

Figure 2: The Museum of the Future @Dubai Future Foundation 2019 (http://www.museumofthefuture.ae/).

\section{CASE STUDY AND LEARNINGS}

In this section, we (the authors representing InvisibleStudio) delve into what has been learnt by applying digital prototyping principles and methodologies in three recent (from 2017 to early 2019) case histories, namely the Museo Egizio of Turin, the Imperial War Museums London and the Poldi Pezzoli House Museum of Milan.

Details about specific projects are summarised as they are still on-going and not formally released. However, we discuss the advantages and challenges that we have encountered when staff members of our host museums utilised a prototyping approach in designing three different digital products, as follows: 
1. Audio/Video mobile apps

2. Multimedia in the galleries

3. Museum websites

Note that wherever we use the term 'design thinking' or 'co-design' - these are related to the Stanford's d.school approach. The d.school has developed a five-step process: interviewing and observing in the field; synthesizing insights; generating ideas; building prototypes; and testing with users (Plattner 2011, Mitroff Silvers, Wilson, \& Rogers 2013).

\subsection{Audio/video mobile apps}

Audio guides and video guides are among the most pervasive interpretation tools museums offer their visitors. Therefore, it is feasible for museums to experiment with human centred design techniques to better understand users' needs, as the British Museum achieved for its audio guide (Mannion, Sabiescu \& Robinson 2015, 2016). Particularly, audio and video content are difficult to correct after production, while text and images can be somewhat easier to change. Consequently, we think it is very important to start the actual audio/video production after the research and testing phases.

In our projects we experimented with three types of prototypes: audio, paper and digital -described below.

\subsubsection{Audio prototyping}

Audio prototyping often means creating "quick and dirty" audio files to be tested for their length, content, and tone of voice. While audio files are relatively easy to produce - a smartphone with a standard microphone and earphones can produce a good quality audio prototype - we found in our experience that the rate of museums producing a test version of their audio guides is still surprisingly low.

The production process for many museums is to involve curators producing the text, which are then passed onto a production company to produce the final audio guide using professional readers and additional sound effects.

A drawback with this process is that curators tend to produce text, which is scientifically or historically accurate but not optimised for the end user in an audio format.
Reading and recording texts and then testing them in the galleries is a powerful tool for museum curators to improve the content and make it more enjoyable. Audio files can be tested by curators on themselves, on other colleagues, or on random and targeted visitors in order to gain different levels of knowledge about responses to the subject and to the museum. Curators can also easily mount the different audio files in a draft "audio tour" using free websites like IZI.Travel (https://izi.travel/en); this way users can be asked to follow a full tour by themselves without the presence of the author, who might bias the tester's perception.

We have noticed significant results in situations in which curators record and test their own material. This often resulted in the use of simpler words and shorter texts. Just by reading the content out loud curators realised that some sentences were cacophonic or over-complicated. Moreover, the listening experience when standing and walking in the galleries is quite different from reading the same text at one's own desk and can lead to refinements to the original text.

Curators were often reluctant to have other people listen to their recordings, mainly due to lack of confidence about their read out-loud skills and/or voice quality which were not considered comparable to professional actors. This was seen as impacting the quality of the reading. One way to overcome this problem was to use $A / B$ testing, i.e. producing two different versions of the same audio, e.g. different content, length, or tone of voice, and then inviting users to listen to each version and choose their preferred version. In this way it was possible to judge specific elements for quality for the published version.

Video content is more difficult to test, because the difference between a sample video produced quickly with a smartphone and a professionally shot and edited version can be qualitatively different enough to impact test results. In this case, it can be more efficient to secure a draft version provided by the production group to be tested directly in the galleries.

\subsubsection{Paper prototyping}

While audio prototyping is a robust tool for testing content and length of the audio portion of the audio guide, it cannot be easily applied to verify navigation or other non-audio features. In this case paper and digital prototyping can be better applied. 


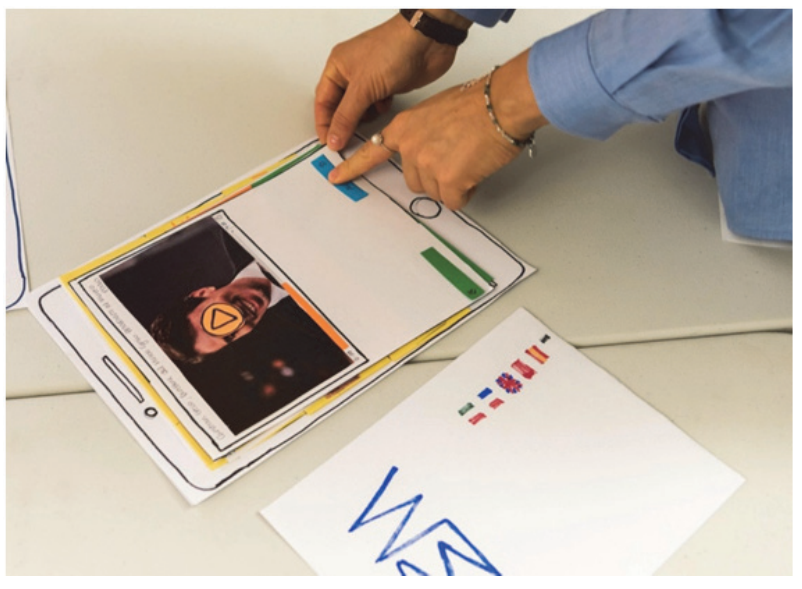

Figure 3: Paper Prototyping of a tablet app (Source: Invisible Studio (O2018).

Paper prototyping involves creating paper versions of various screenshots to simulate navigation. Users can interact with these as if they were a real digital interface, i.e. clicking on links, enlarging images etc. Although it may seem counterintuitive, paper prototyping can be very effective in highlighting basic usability problems and navigation flaws. It can also make people more willing to suggest modifications because the "draft" stage of the prototype is self-evident. Moreover, an approach with paper prototypes brings in visitors as co-creators instead of simply passive users. (Boiano \& Gaia 2017).

Paper prototyping however has some disadvantages; for example, there are certain animations, such as "fade" effects, that cannot be realistically simulated, and people tend to interact slightly differently with the paper prototype than they might with a keyboard and digital prototype (Gao 2018). Speed of interaction is also affected: switching from a screen to another on paper is considerably slower than with a digital prototype.

\subsubsection{Digital prototyping}

Another way of prototyping mobile applications is to build quick interactive prototypes through the use of specific apps or software. There are several available applications, e.g. Marvel (https://marvelapp.com/pop/) and Invision (https://www.invisionapp.com/), which can assist in building digital interactive prototypes for mobile users.

Prototyping is a balance of time and achieving realism; the more realistic, the more time and effort required to put into the prototype. From our experience, realistic prototypes should ideally come at a later stage when there is an opportunity to focus on the design details. Low-fidelity prototypes are recommended for the early stage, as they are better for sketching out the basic navigation and interaction. Their flexibility also allows for quicker changes.

Finally, if the museum aims to prototype a different digital product, such as a mobile chatbot, a good way to test is to invite real people to act as the chatbots. One can use existing Messenger platforms like Facebook Messenger or Whatsapp, with a predefined script from which they can copy and paste the answers. The authors have tested this feature while developing the Milan House Museum chatbots (Boiano et al. 2018) with good results.

\subsection{Multimedia in the Galleries}

Testing multimedia installations in the galleries can be undertaken with Paper/cardboard prototyping, Role-playing, Digital prototyping and/or a combination of all these methods.

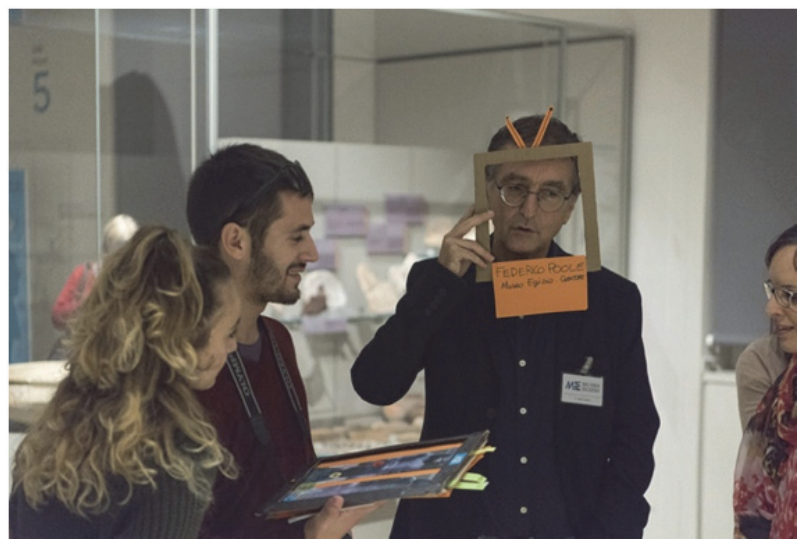

Figure 4: Video Simulation in gallery testing. Source: Invisible Studio (O2018.

One factor to take into consideration is whether or not testing can be conducted within the actual context of the galleries. During our projects we have experienced this as an important aspect because the gallery context is very specific and can significantly influence test results. For example, in one testing round, an audio installation was being evaluated, and while it gave good results in offices, when tested in the noisy and distracting environment of the galleries, it gave completely different and less satisfying results. 


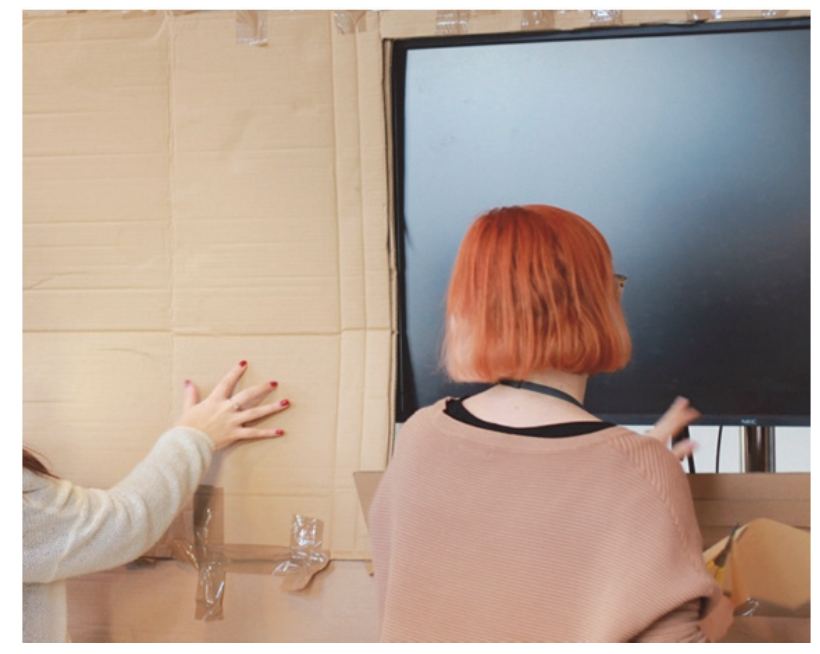

Figure 5: Building a cardboard encasing around a screen for gallery testing (Source: Invisible Studio C2018).

Effective tools for testing in the galleries include:

- Tablets and interactive screens (e.g. movable interactive whiteboards) with or without cardboard encasings;

- Mobile projectors (e.g. with movable screens if necessary);

- Portable audio equipment, but need to be powerful enough to convey realistic results;

- Paper prototypes of digital interactions to test basic content and navigation;

- Role Playing, with museum staff enacting services or even digital installations. For example, in a museum project an audio service was tested with a curator offering real time information on objects chosen by users.

If testing in the galleries is not possible, due to technical limitations or multimedia cannot be fitted in a new exhibition environment that is in planning stage, then the lack of the gallery context will need to be factored in. This means that, in order to be meaningful, the testing should focus on specific aspects of the interaction or on the content, instead of testing the whole experience which cannot be recreated in its entirety.

\subsection{Museum website prototyping}

Museum websites can be effectively prototyped using presentation software, such as Keynote or Powerpoint. Websites can also be effectively tested on remote visitors. One can either produce the interface with Google Slides and then share it with test users, or apply screen sharing capabilities of teleconferencing software, such as Skype, Zoom or Google Hangout to organise remote testing sessions.
Paper prototyping can be considered for website testing and prototyping. The testing recommendations outlined for audio/video guides and mobile apps can be effectively used for museum websites as well. However, we recommend museum staff to prioritise the mobile version. The use of Mobile First indexing (https://developers.google.com/search/mobilesites/mobile-first-indexing) means Google defaults to the mobile version. Visitor statistics further confirm that mobile traffic surpasses desktop browser traffic, according to the Statista survey in 2018 (Statista 2018). Visitors are likely to use smartphones to consult the museum website both prior to the visit and during their visit in the galleries.

\section{CHALLENGES}

One of the most common challenges in prototyping is time constraint. Prototyping can be seen as time consuming, and contributing to project delays with already tight deadlines. Notwithstanding it can be conversely argued that prototyping in the design phase often leads to savings in the medium to long term and resulting in better quality and user satisfaction. It is also knowing when prototyping is appropriate and what stages to apply prototyping in a project lifecycle.

Participatory innovation itself opens up to both potential and challenges for museums. It feasibly relies on appropriate governance, resource and infrastructure, and not least on stakeholder contributions to be truly inclusive (Simon 2010, Mclean 2011, Anttiroiko 2016). Depending on scale and other attributes, there are further challenges in managing complexity and intellectual property in regard to innovation outcomes themselves. To offset some of these challenges, this might entail clearer roles in participatory innovation processes for more diverse community members and participants.

\section{CONCLUSION}

The sector has a strong provenance with decades long experience in piloting emerging and embedded technologies through prototyping, and in its understanding of user-centric interaction in building digital experiences. In this way, prototyping is not only an efficient and creative process in terms of production, but it is a critical means to strengthen the relationship between museums and its audiences by making them an essential part of museum design and production processes.

Similarly, there is clear evidence of the potential of cultural heritage organisations to play a significant role in advancing participatory innovation. Bridging 
expert knowledge with the knowledge of audiences and community participants can bring further opportunities to scale innovation, and to better address the major socio-technological and environmental challenges which we all share.

\section{REFERENCES}

Anttiroiko, A. V. (2016) City-as-a-Platform: The Rise of Participatory Innovation Platforms in Finnish Cities. Sustainability, 8(9), pp2-31.

Bødker, K., Kensing, F., and Simonsen, J. (2004) Participatory IT design: Designing for business and workplace realities. Cambridge, MA, USA: MIT Press.

Boiano, S. and Gaia, G. (2017) How We Helped the Museo Egizio of Turin to Re-Think its Audio Guide Using Design Thinking and Paper Prototyping.

https://medium.com/@invisiblestudio/how-wehelped-the-egyptian-museum-of-turin-to-re-thinkits-audioguide-using-design-thinking6a27b080b3de (retrieved 16 March 2019).

Boiano, S., Borda, A., Gaia, G., Rossi S., and Cuomo, P. (2018) Chatbots and New Audience Opportunities for Museums and Heritage Organisations. In Proceedings Electronic Visualisation and the Arts (EVA 2018) London, UK, 9-13 July 2018.

https://dx.doi.org/10.14236/ewic/EVA2018.33 (retrieved 16 March 2019).

Bridge, S. (2018) Dubai's Museum of the Future plans high-tech visitor experiences. Arabian Business May 24, 2018.

https://www.arabianbusiness.com/technology/3961 78-wkd-dubais-museum-of-the-future-seeks-hightech-visitor-experiences (retrieved 18 March 2019)

Buur, J. and Matthews, B. (2008) Participatory innovation. Int. J. Innov. Manag, 12, pp.255-273.

Cross, N., Dorst, K. \& Roozenburg, N. (eds) (1992) Research in Design Thinking, Delft University Press.

Dawson, B., Smith Hale, F., \& Corbeil, S. (2017) Open innovation: Open movements and the role of a museum in the 21st century. MW2017: Museums and the Web, 16 February 2017. http://mw17.mwconf.org/paper/open-innovationopen-movements-and-the-role-of-a-museum-in-the21st-century/ (retrieved 9 January 2019).

Chesborough, H. (2003) Open Innovation: The New Imperative for Creating and Profiting from Technology. HBS Press.
Ciecko, B. and Turoczy, R. (2017) Brendan Ciecko and Rick Turoczy in conversation about startups and accelerators in museums. Museum Next, Portland 2017.

https://www.museumnext.com/insight/startupsaccelerators-museums/ (retrieved 18 March 2019).

Eid, H. (2016) The Museum Innovation Model: A museum perspective on innovation. MW2016: Museums and the Web 2016.

https://mw2016.museumsandtheweb.com/paper/th e-museum-innovation-model-a-museum-

perspective-to-innovation/ (retrieved 13 March 2019).

Eskelinen J., et al. (2015) Citizen-driven innovation: a guidebook for city mayors and public administrators. World Bank, Washington, DC, and European Network of Living Labs.

http://openknowledge.worldbank.org/handle/10986/ 21984 (retrieved 7 Jan 2019).

Gao, S. (2018) Paper Prototyping-How-to, Pros \& Cons, and the Struggles of Guerrilla Usability Testing. https://medium.com/@shengao/paperprototyping-how-to-pros-cons-and-the-struggles-ofguerrilla-usability-testing-5546dd446d5e (retrieved 14 March 2019).

Hegley, D., Tongen, M, and David, A. (2016) The Agile museum. MW2016: Museums and the Web 2016.

https://mw2016.museumsandtheweb.com/paper/th e-agile-museum/ (retrieved 18 March 2019)

Lepik, K. L., Krigul, M., and Terk, E. (2010) Introducing Living Lab's Method as Knowledge Transfer from One Socio-Institutional Context to Another: Evidence from Helsinki-Tallinn CrossBorder Region. Journal of Universal Computer Science, 16(8), pp.1089-1101.

Leyronas, S. et al. (2018) How fab labs help meet digital challenges in Africa. The Conversation, July 5, 2018. https://theconversation.com/how-fab-labshelp-meet-digital-challenges-in-africa-99202 (retrieved 18 March 2019).

Mannion, S., Sabiescu, A. and Robinson, W. (2016) Innovate or stagnate: Disrupting the conventional audio guide. MW2016: Museums and the Web 2016.

https://mw2016.museumsandtheweb.com/paper/in novate-or-stagnate-disrupting-the-conventionalaudio-guide/ (retrieved 16 March 2019).

Mannion, S., Sabiescu, A. and Robinson, W. (2015) An audio state of mind: Understanding behaviour around audio guides and visitor media. MW2015: Museums and the Web 2015.

http://mw2015.museumsandtheweb.com/paper/anaudio-state-of-mind-understanding-behviouraround-audio-guides-and-visitor-medial (retrieved 16 March 2019). 
McLean, K. (2011) Whose Questions, Whose Conversations? In Adair, B., Filene, B. and Kolosky, L. (eds), Letting Go? Sharing Historical Authority in a User-Generated World. Philadelphia: Pew Center for Arts \& Heritage, pp.70-79.

Merrit, E. (2017) Failure Failing Toward Success: The Ascendance Of Agile Design. Center for the Future Of Museums Blog, 1 May 2017. https://www.aam-us.org/2017/05/01/failure-failingtoward-success-the-ascendance-of-agile-design/ (retrieved 18 March 2019).

Mitroff Silvers, D. et al. (2014) From Post-its to Processes: Using Prototypes to Find Solutions. MW2014: Museums and the Web 2014. https://mw2014.museumsandtheweb.com/paper/fro m-post-its-to-processes-using-prototypes-to-findsolutions/ (retrieved 8 March 2019).

Mitroff Silvers, D., Wilson, M. and Rogers, M. (2013) Design thinking for visitor engagement: Tackling one museum's big challenge through human-centred design. In: N. Proctor and R. Cherry (eds), Museums and the Web 2013. Silver Spring, MD.

http://mw2013.museumsandtheweb.com/paper/des ign-thinking/ (retrieved 18 March 2019).

Mitroff Silvers, D. (2016) The British Museum: Running Design Sprints in Museums. Sprint Stories 26 Aug 2016. https://sprintstories.com/runningdesign-sprints-in-museums-41a64a8aff50 (retrieved 18 March 2019).

Muller, L., Edmonds, E. and Connell, M. (2006) Living laboratories for interactive art, CoDesign, 2:4, 195-207. DOI: 10.1080/15710880601008109

Murphy, O. (2018) Coworking Spaces, Accelerators and Incubators: Emerging Forms of Museum Practice in an Increasingly Digital World. Special Issue: Museums in a Digital World. 70(1-2), pp.6275.
Owens, T. (2012) The Crowd and The Library. http://www.trevorowens.org/2012/05/the-crowdand-the-library/ (retrieved 18 March 2019).

Rey, S. (2017) Museomix: lessons learned from an open creative hackathon in museums. In European Tangible Interaction Studio (ETIS 2017), Jun 2017, 1861, pp.5.

Plattner, H., Meinel, C. and Leifer, L. J., (eds) (2011) Design thinking: understand, improve, apply. Understanding innovation. Berlin; Heidelberg: $\quad$ Springer-Verlag. pp.xiv-xvi. doi:10.1007/978-3-642-13757-0

Schrage, M. 1(996) Cultures of prototyping. In Bringing design to software, Terry Winograd (ed.). ACM, New York, NY, USA, 191-213. DOI: 10.1145/229868.230045

Simon, N. (2010) The Participatory Museum. http://www.participatorymuseum.org/read/ (accessed 12 January 2019).

Statista (2018) Percentage of all global web pages served to mobile phones from 2009 to 2018. https://www.statista.com/statistics/241462/globalmobile-phone-website-traffic-share/ (retrieved 18 March 2019)

Szebeko, D. and Tan, L. (2010) Co-designing for society. AMJ 2010, 3(9), 580-590. DOI:10.4066 / AMJ.2010.378

Turnbull D. and Connell, M. (2011) Prototyping Places: The museum. In L. Candy \& E. Edmonds (eds), Interacting: Art, Research and the Creative Practitioner. Libri Publications.

Vilariño, F. and Karatzas, D. (2018) The Library Living Lab: A Collaborative Innovation Model for Public Libraries. Technology Innovation Management Review, 8(17-25).

DOI:10.22215/timreview/1202 